\title{
Stability in a parallel resonant circuit with active load
}

\author{
Usmanov E. $G^{1}$ \\ ${ }^{1}$ Tashkent State Technical University, Tashkent, 100095, Uzbekistan
}

\begin{abstract}
This article examines the stability of excited oscillations in resonant circuits in order to determine the possibility of their application to control thyristors in the function of changing the input voltage value. In resonant circuits connected to a voltage source with a low internal resistance, the occurrence of stable oscillations depends significantly on the value of the parameters of the circuit under consideration.
\end{abstract}

Key words: stationary oscillations, phase of oscillations, stability, state of quilibrium.

\section{Introduction}

In resonant circuits connected to a voltage source with a low internal resistance, for a certain combination of parameters, the excitation of oscillations at the fundamental frequency is observed, the initial phase of which has a shift with respect to the phase of the applied voltage. Moreover, the phase of the excited oscillations depends on the magnitude of the applied emf. [1-6].

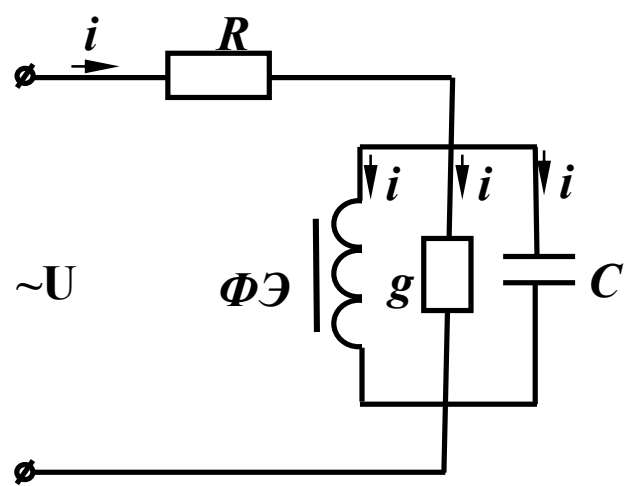

Figure: 1. Equivalent circuit of a parallel resonant circuit with active resistance connected in series to it.

This article discusses the stability of stationary oscillations arising on an unbranched section of the circuit (Fig. 1) in order to determine the possibility of them. thyristors as a function of voltage [7-10].

The investigated circuit is described by the following differential equation:

$$
u=w \frac{d \phi}{d t}+R i
$$

Where

$$
\begin{aligned}
& i=i_{C}+i_{g}+i_{\Phi \ni} \\
& \text { Here } i_{C}=w C \frac{d^{2} \phi}{d t^{2}} ; i_{g}=w g \frac{d \phi}{d t} ; i_{\Phi \ni}=\frac{K}{w} \phi^{7}
\end{aligned}
$$

Substituting the corresponding values of the currents into equation (1), we obtain

$$
u=w \frac{d \phi}{d t}+w C R \frac{d^{2} \phi}{d t^{2}}+w g R \frac{d \phi}{d t}+\frac{K R}{w} \phi^{7}
$$

Introducing the basic and dimensionless quantities corresponding to equation (2), as well as dimensionless coefficients:

$$
\begin{aligned}
y & =\frac{u}{U_{\sigma}} ; \quad x=\frac{\phi}{\Phi_{\sigma}} ; \quad \Phi_{\sigma}=\sqrt[\sigma]{\frac{64 \omega^{2} w^{2} C}{35 K}} ; \\
U_{\sigma} & =\omega w \Phi_{\sigma} ; \quad \tau=\omega t \quad \delta=\omega C R ; \quad \xi=g R .
\end{aligned}
$$

We rewrite equation (3)

$$
y=\delta \frac{d^{2} x}{d \tau^{2}}+(1+\xi) \frac{d x}{s \tau}+\delta \frac{64}{35} x^{7}
$$

Solving this differential equation, we obtain:

$$
\begin{array}{r}
-y_{m} \operatorname{Sin} \psi=2 \delta \frac{d X_{m}}{d \tau}+(1+\xi) X_{m} \\
y_{m} \operatorname{Cos} \psi=2 \delta \delta_{m} \frac{d \psi}{d \tau}+\delta X_{m}\left(X_{m}^{6}-1\right) X_{m} .
\end{array}
$$

Stationary solution

$$
\begin{gathered}
-y_{m} \operatorname{Sin} \psi=(1+\xi) X_{m} \\
y_{m} \operatorname{Cos} \psi=\delta X_{m}\left(X_{m}^{6}-1\right) X_{m}
\end{gathered}
$$

Solving together equations (4) and (5) we obtain the amplitude value of the input voltage in relative units.

$$
y_{m}=X_{m} \sqrt{(1+\xi)^{2}+\delta^{2}\left(X_{m}^{6}-1\right)} \text {. }
$$

With a sinusoidal mains voltage, both natural and forced oscillations occur in the ferroresonant circuit. at certain ratios of parameters in the current-voltage characteristic of the circuit, it can cause the appearance of a region of ambiguity of solutions. Therefore, we will consider the issues of stability of the obtained solutions for the stationary state of the ferroresonant circuit [11$16]$.

Let us consider the question of the stability of the obtained solution, based on the Lyapunov theory. For the circuit under consideration, we rewrite the differential equation (4) and (5) as follows, taking the generally accepted notation 


$$
\begin{aligned}
& 2 \frac{d X_{m}}{d \tau}=-\frac{y_{m}}{\delta} \operatorname{Sin} \psi-\frac{1+\xi}{\delta} X_{m}=F=A\left(X_{m} ; \psi\right) \\
& 2 \frac{d \psi}{d \tau}=-\frac{y_{m}}{\delta X_{m}} \operatorname{Cos} \psi+\left(X_{m}^{6}-1\right)=B\left(X_{m} ; \psi\right)
\end{aligned}
$$

The equilibrium state is determined by the roots of the system of equations $A\left(X_{m} ; \psi\right)$ and $B\left(X_{m} ; \psi\right)$

Consider some equilibrium state $\boldsymbol{x}_{\boldsymbol{k}}$ and $\boldsymbol{\psi}_{\boldsymbol{k}}$.

According to the accepted methodology.

$$
x=x_{k}+\varepsilon ; \quad \psi=\psi k+\eta
$$

In new variables, equation (9) has the form:

$$
\frac{d \varepsilon}{d \tau}=A\left(x_{k}+\varepsilon ; \psi_{k}+\eta\right) ; \quad \frac{d \eta}{d \tau}=B\left(x_{k}+\varepsilon ; \psi_{k}+\eta\right)
$$

The variables $\boldsymbol{\varepsilon}$ and $\boldsymbol{\eta}$ represent the displacement from the equilibrium state. We expand the functions A and B into a Taylor series in $\boldsymbol{\varepsilon}$ and $\boldsymbol{\eta}$ near the point $\boldsymbol{x}_{\boldsymbol{k}}$ and $\boldsymbol{\psi}_{\boldsymbol{k}}$, limiting ourselves to the expansion terms

$$
\begin{aligned}
& \frac{d \varepsilon}{d \tau}=A\left(x_{k} ; \psi_{k}\right)+\frac{d A\left(x_{k} ; \psi_{k}\right)}{d \tau}+\frac{d B\left(x_{k} ; \psi_{k}\right)}{d \psi}+\ldots . \\
& \frac{d \eta}{d \tau}=B\left(x_{k} ; \psi_{k}\right)+\frac{d A\left(x_{k} ; \psi_{k}\right)}{d \tau}+\frac{d B\left(x_{k} ; \psi_{k}\right)}{d \psi}+\ldots .
\end{aligned}
$$

that is, a linear equation with constant coefficients. According to Lyapunov's theory, the system of the first approximation is not stable if the real parts of both roots of the characteristic equation are equal to zero or if one root is equal to zero and the second is negative, the coefficients of the characteristic equation of the system of the first approximation are $\lambda^{2}+p \lambda+q=0$ determined by the expressions

$$
\begin{gathered}
p=-\left|\begin{array}{ll}
\frac{d A\left(x_{k} ; \psi_{k}\right)}{d x}+\frac{d B\left(x_{k} ; \psi_{k}\right)}{d \psi}
\end{array}\right| \\
q=\left|\begin{array}{ll}
\frac{d A\left(x_{k} ; \psi_{k}\right)}{d x} & \frac{d A\left(x_{k} ; \psi_{k}\right)}{d \psi} \\
\frac{d B\left(x_{k} ; \psi_{k}\right)}{d x} & \frac{d B\left(x_{k} ; \psi_{k}\right)}{d \psi}
\end{array}\right|
\end{gathered}
$$

The condition for the stability of the system according to the Hurwitz criterion is

$$
\boldsymbol{p}>\boldsymbol{0}, \boldsymbol{q}>\boldsymbol{0}
$$

To determine the question of stability of the considered ferroresonant circuit, we use the given theory of Lyapunov [17-19].

From system (9) we define

$$
\begin{array}{lrl}
\frac{d A}{d x}=-\frac{1+\xi}{\delta} & \frac{d A}{d \psi}=-\frac{y_{m}}{\delta} \operatorname{Cos} \psi \\
\frac{d B}{d x}=-\frac{y_{m}}{\delta X_{m}} \operatorname{Cos} \psi+6 X_{m}^{5} & \frac{d B}{d \psi}=\frac{y_{m}}{\delta X_{m}} \operatorname{Sin} \psi
\end{array}
$$

From (6) and (7) we define

$$
\begin{aligned}
& \operatorname{Sin} \psi=-(1+\xi) \frac{X_{m}}{y_{m}} \\
& \operatorname{Cos} \psi=\delta\left(X_{m}^{6}-1\right) \frac{X_{m}}{y_{m}}
\end{aligned}
$$

Let us substitute in (11) the values of $\operatorname{Sin} \psi$ and Cos\%. Then we will have

$$
\begin{array}{ll}
\frac{d A}{d x}=-\frac{1+\xi}{\delta} & \frac{d A}{d \psi}=\left(1-X_{m}^{6}\right) X_{m} \\
\frac{d B}{d x}=-\frac{1-X_{m}^{6}}{X_{m}}+6 X_{m}^{6} & \frac{d B}{d \psi}=-\frac{1+\xi}{\delta}
\end{array}
$$

From (12) by expressions (10) we obtain the roots of the characteristic equation

$$
\begin{gathered}
p=\frac{2(1+\xi)}{\delta} \\
q=\left(\frac{1+\xi}{\delta}\right)^{2}-\left(1-X_{m}^{6}\right)^{2}-6 X_{m}^{6}\left(1-X_{m}^{6}\right)
\end{gathered}
$$

The first condition $\boldsymbol{p}>\boldsymbol{0}$ does not limit the stability of the solution, since it is $(1+\xi) / \delta$ always greater than zero. Therefore, to determine the stability of the solution, it is sufficient to calculate the value of q [20-22].

\section{Conclusions}

Have shown that the solution corresponding to a steady state depends significantly on the values of the parameters $\boldsymbol{C}, \boldsymbol{g}$ and $\boldsymbol{R}$.

\section{References}

1. E.G. Usmanov, A.N. Rasulov, M.K. Bobojanov, R.Ch. Karimov. Non-contact voltage relay for switching windings of a boost transformer // E3S Web of Conferences $139,01079 \quad$ (2019), doi.org/10.1051/e3sconf/201913901079

2. R.Ch.Karimov, MK Bobojanov, AN Rasulov, EG Usmanov. Controlled switching circuits based on nonlinear resistive elements // E3S Web of Conferences 139, 01039 (2019), doi.org/10.1051/e3sconf/201913901039

3. Bobojanov M.K., Usmanov E.G., Abduraimov E.H., Karimov R.Ch. Resistive time delay switches // Scientific journal «European Science Review» (ISSN: 2310-5577). Vienna (Austria), January-February. - №12. - PP.210-212 (2018).

4. Rakhmonov,I., Berdishev,A., Khusanov,B.M, Khal iknazarov, U., Utegenov, U. General characteristics of networks and features of electricity consumers in rural areas//IOP Conference Series: Materials Science and Engineering, 2020, 883(1), 012104.

5. Khakimov, H.T., Shayumova, Z.M., Kurbanbaeva, Z.K., Khusanov, B.M. Development of optimal modes and mathematical models of energy performance of electric steelmaking production//E3S Web of Conferences, 2019, 139, 01076

6. Saidkhodjaev A G, Najimova A M and Bijanov A K 2019 Method for determining the maximum load of consumers in city power supply systems E3S Web Conf 139 doi:10.1051/e3sconf/201913901078.

7. Taslimov A D, Rakhmonov I U 2019 Optimization of complex parameters of urban distribution electric networks Journal of Physics: Conference Series 1399 doi:10.1088/1742-6596/1399/5/055046

8. Rakhmonov I U, Niyozov N N 2019 Optimization setting of steel-smelting industry in the issue of alloy 

$\begin{array}{lccc}\text { steels } & E 3 S & \text { Web Conf } \\ \text { doi:10.1051/e3sconf/201913901077 }\end{array}$

139

9. Mannanov U., Toshov J., Toshniyozov L. Perspective Solutions for the Design of Drilling Tools / E3S Web of Conferences 105, 03027 (2019) IVth International Innovative Mining Symposium, https://doi.org/10.1051/e3sconf/201910503027

10. Azamatovich, A.N., Amrillo, M.B, Burievich, T.J., Umarxanoxich, J.R., Shavkatovich, Z.A. A complex of methods for analyzing the working fluid of a hydrostatic power plant for hydraulic mining machines / International Journal of Advanced Science and Technology. Volume 29, Issue 5 Special Issue, 28 March 2020, Pages 852-855

11. Rakhmonov I U, Reymov K M and Shayumova Z M 2019 The role information in power management tasks. E3S Web Conf 139 doi:10.1051/e3sconf/201913901080 12. Hoshimov, F.A., Bakhadirov, I.I., Erejepov, M., Djumamuratov, B. (2019) Development of method for normalizing electricity consumption E3S Web Conf 139 doi:10.1051/e3sconf $/ 201913901074$

13. Rakhmonov I U, Tovbaev A N, Nematov L A and Alibekova T Sh 2020 Development of forecasted values of specific norms for the issues of produced products in industrial enterprises Journal of Physics: Conference Series 1515 doi:10.1088/1742-6596/1515/2/022050

14. Rakhmonov I U, Nematov L A, Niyozov N N, Reymov K M and Yuldoshev T M 2020 Power consumption management from the positions of the general system theory Journal of Physics: Conference Series 1515 doi:10.1088/1742-6596/1515/2/022054

15. Rakhmonov I U, Reymov K M, Najimova A M, Uzakov B T and Seytmuratov BT 2019 Analysis and calculation of optimum parameters of electric arc furnace Journal of Physics: Conference Series 1399 doi:10.1088/1742-6596/1399/5/055048

16. Taslimov A D, Berdishev A S, Melikuzuev M V and Rakhimov F M 2019 Method of selecting parameters of cable lines distributive networks $10 \mathrm{kv}$ in uncertainty conditions $\quad$ E3S $\quad$ Web $\quad$ Conf 139 doi:10.1051/e3sconf $/ 201913901082$

17. Taslimov A D, Berdishev A S, Melikuziyev M V and Rakhimov F M 2019 Method of choosing the unification of cable sections of electric network cables under conditions of load development uncertainty E3S Web Conf 139 doi:10.1051/e3sconf/201913901081

18. Karimov R.Ch., Shamsiyev K., and others. IOP Conf. Series: Materials Science and Engineering, 883(1), 012142, (2020). doi:10.1088/1757-899X/883/1/012142

19. Karimov R.Ch., Shamsiyeva N. and others. IOP Conf. Series: Materials Science and Engineering, 883(1), 012120, (2020). doi:10.1088/1757-899X/883/1/012120

20. Burievich, T.J. The questions of the dynamics of drilling bit on the surface of well bottom// Arch. Min. Sci. -Poland. - Vol. 61 (2016). - №2. - P. 279-287. DOI 10.1515/amsc-2016-0020.

21. Toshniyozov, L.G., Toshov, J.B. Theoretical and experimental research into process of packing in drilling// Mining Informational and Analytical Bulletin Volume 2019, Issue 11, 2019, Pages 139-151. DOI: 10.25018/0236-1493-2019-11-0-139-151.
22. G.R.Rafikova,

M.R.Ruzinazarov, S.K.Makhmutkhonov. E3S Web of Conferences, 139, 01075 , 